This item was submitted to Loughborough's Research Repository by the author.

Items in Figshare are protected by copyright, with all rights reserved, unless otherwise indicated.

\title{
The use of an air bubble curtain to reduce the received sound levels for harbor porpoises (Phocoena phocoena)
}

PLEASE CITE THE PUBLISHED VERSION

http://dx.doi.org/10.1121/1.3626123

PUBLISHER

(c) Acoustical Society of America

VERSION

VoR (Version of Record)

LICENCE

CC BY-NC-ND 4.0

REPOSITORY RECORD

Lucke, Klaus, Paul A. Lepper, Marie-Anne Blanchet, and Ursula Siebert. 2019. "The Use of an Air Bubble Curtain to Reduce the Received Sound Levels for Harbor Porpoises (phocoena Phocoena)". figshare. https://hdl.handle.net/2134/9592. 
This item was submitted to Loughborough's Institutional Repository (https://dspace.lboro.ac.uk/) by the author and is made available under the following Creative Commons Licence conditions.

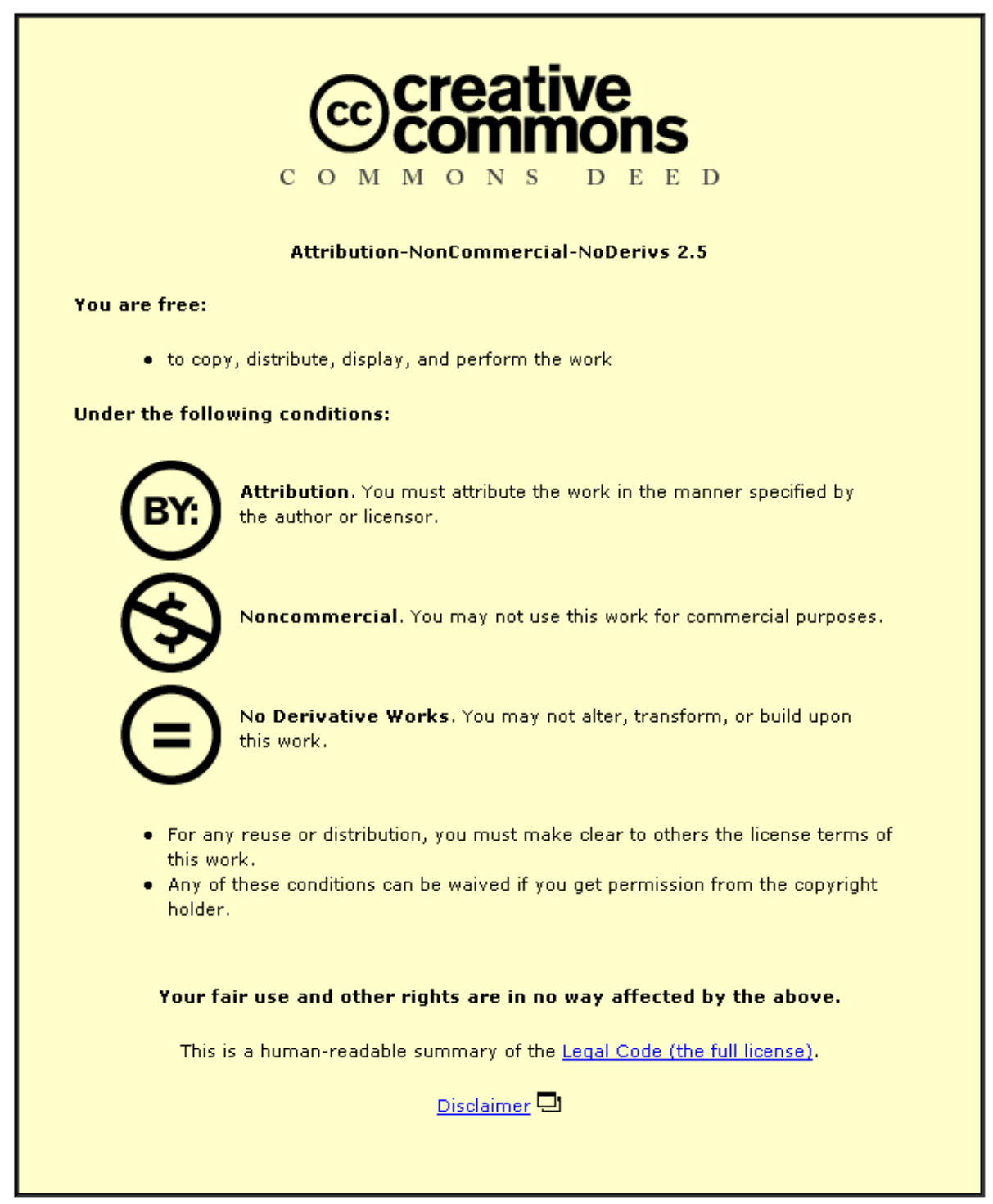

For the full text of this licence, please go to: http://creativecommons.org/licenses/by-nc-nd/2.5/ 


\title{
The use of an air bubble curtain to reduce the received sound levels for harbor porpoises (Phocoena phocoena)
}

\author{
Klaus Lucke ${ }^{\text {a) }}$ \\ Forschungs- und Technologiezentrum Westküste, Christian-Albrechts-Universität zu Kiel, 25761 Büsum, \\ Germany \\ Paul A. Lepper \\ Advanced Signal Processing Group, Department Electronic and Electrical Engineering, \\ Loughborough University, Loughborough LE11 3TU, United Kingdom \\ Marie-Anne Blanchet \\ Fjord and Baelt, Margrethes Plads 1, 5300 Kerteminde, Denmark \\ Ursula Siebert \\ Forschungs- und Technologiezentrum Westküste, Christian-Albrechts-Universität zu Kiel, 25761 Büsum, Germany
}

(Received 23 July 2010; revised 30 December 2010; accepted 6 January 2011)

\begin{abstract}
In December 2005 construction work was started to replace a harbor wall in Kerteminde harbor, Denmark. A total of 175 wooden piles were piled into the ground at the waters edge over a period of 3 months. During the same period three harbor porpoises were housed in a marine mammal facility on the opposite side of the harbor. All animals showed strong avoidance reactions after the start of the piling activities. As a measure to reduce the sound exposure for the animals an air bubble curtain was constructed and operated in a direct path between the piling site and the opening of the animals' semi-natural pool. The sound attenuation effect achieved with this system was determined by quantitative comparison of pile driving impulses simultaneously measured in front of and behind the active air bubble curtain. Mean levels of sound attenuation over a sequence of 95 consecutive pile strikes were $14 \mathrm{~dB}$ (standard deviation (s.d.) $3.4 \mathrm{~dB}$ ) for peak to peak values and $13 \mathrm{~dB}$ (s.d. $2.5 \mathrm{~dB}$ ) for SEL values. As soon as the air bubble curtain was installed and operated, no further avoidance reactions of the animals to the piling activities were apparent.
\end{abstract}

(C) 2011 Acoustical Society of America. [DOI: 10.1121/1.3626123]

PACS number(s): 43.50.Gf, 43.80.Nd, 43.50.Pn [JJF]

Pages: $3406-3412$

\section{INTRODUCTION}

The diversity and amount of anthropogenic activities at sea has increased on average over the past decades. Numerous of these activities are linked to the emission of intense sound into the marine environment. Intense underwater sound has been identified as a potential threat especially for fish and marine mammals. Concern about sound-induced effects on these taxa was raised especially with regard to the construction of offshore wind turbines (Tougaard et al., 2003; Madsen et al., 2006), the use of explosives (see Richardson et al., 1995; Southall et al., 2007), seismic airguns for marine geophysical surveys conducted for hydrocarbon exploration [National Research Council (NRC), 2000, 2005; Gordon et al., 2004) and military sonars (Richardson et al., 1995; Southall et al., 2007]. The wider implications of the effects of pile driving are currently seen in the extensive expansion of near shore (bridge building) and offshore construction (California Department of Transportation, 2001; Tougaard et al., 2009).

The acoustic characteristics of marine piling in the case of offshore wind park developments has received some attention (Robinson et al., 2007; DeJong and Ainslee, 2008; Matuschek and Betke, 2009); however, still very little peer-reviewed data

\footnotetext{
a) Author to whom correspondence should be addressed. Electronic mail: lucke@ftz-west.uni-kiel.de
}

outside of these studies is currently reported on larger pile diameters (2.5-6 m). Some measurements of piling of smaller pile diameters used for seabed foundations, harbor construction, bridge building, etc., have also been carried out. Reyff (2009) reports measured data for a wide variety of smaller pile diameters from $(0.3-2.4 \mathrm{~m})$ diameter and construction type including steel sheet, steel pile, and concrete for both impact hammers and vibratory piling systems. In this case received levels ranging from $188-220 \mathrm{~dB}$ re $1 \mu \mathrm{Pa}$ (peak: maximum positive or negative observed amplitude) were observed for impact hammers at a range of $10 \mathrm{~m}$. Sound or vibration components generated by impulsive pile driving may also transferred via substrate and then emerge within the water column at some distance from the source (Hawkins, 2009).

The strategies commonly implemented to prevent or mitigate potential negative effects of sound-producing activities on the marine environment include spatial and/or temporal closure of areas, deterrence of species at risk, sound reduction at the source, or sound attenuation within the sound propagation path. In this paper we discuss mitigation through sound attenuation in a specific case of pile driving. This pile driving described herein was conducted in a harbor in the vicinity of the Fjord and Bælt (Kerteminde, Denmark) where three harbor porpoises (Phocoena phocoena) were housed in an outdoor-pool. The harbor porpoise, is a small odontocete species inhabiting mainly coastal waters on the northern hemisphere 
with a functional hearing range reaching at least from $0.5 \mathrm{kHz}$ to $160 \mathrm{kHz}$ (Andersen, 1970; Kastelein et al., 2002). No information on the acoustic tolerance of harbor porpoises to impulsive sounds was available at this time, but on the basis of data on other toothed whale species (Finneran et al., 2002, 2005; Nachtigall et al., 2003, 2004) concern was raised that the exposure to intense pile driving impulses may impair their hearing capabilities. As the harbor porpoises showed strong avoidance reactions after the start of the piling activities an air bubble curtain $(\mathrm{ABC})$ was constructed and operated to reduce the sound exposure for the animals.

Two primary mechanisms play a role in the attenuation of sound in bubbly water. Air and water have strong impedance mismatch, with the water-to-air boundary acting therefore as a near-perfect reflector. Thus, a cloud of bubbles acts as a series of high-impedance scatterers. For an incident sound field the scattering results in a net reduction of sound intensity along the original transmission axis. Second, the incident energy can cause bubbles to resonate, effectively absorbing energy directly. This effect depends on the wavelength of the incident energy and the bubble size. The presence of the bubbles in the water effectively lowers the sound velocity in this region through reflection, refraction, and absorption (Mallock, 1910). The attenuation efficiency can be improved by increasing the total amount of air per unit time released into the water and hence scattering effects. Air bubbles expand while rising to the surface due to the decreasing water pressure. They also tend to fuse to larger bubbles. Therefore, under normal conditions, an air bubble curtain (a stream of bubble from a series of closely spaced release points forming a "wall" or "curtain" of bubble in water column) would contain bubbles ranging from slowly rising micro-bubbles to large bubbles of several centimeters in diameter.

Air bubble curtains have already been tested in several projects (Würsig et al., 2000; California Department of Transportation, 2001; Reyff, 2003a, 2003b; Vagle, 2003; Rodkin and Reyff, 2007; Matuschek and Betke, 2009). However, so far those systems have achieved a wide variation in attenuation effects and were either extremely expensive and/or logistically challenging.

The current study represents a similar opportunity to test the efficacy of an air bubble curtain to reduce impulsive sound from small diameter wooden piles in a near shore environment.

\section{METHODS}

Construction work to replace a harbor wall in Kerteminde harbor was started in December 2005. A total of 175 piles of tropical hard wood of $15 \mathrm{~m}$ length and $40 \mathrm{~cm}$ diameter were piled into the ground using a $14 \mathrm{~kJ}$ gravity pile driver. Up to 430 impacts with an interval of 1.2 to $1.5 \mathrm{~s}$ between successive impacts were needed to drive the individual piles into the ground at the waters edge. The piling activity was conducted in the south-western part of the harbor over a period of 3 months on an irregular schedule of typically 4 working days per week and occasional breaks of up to 2 weeks.

During this time, three harbor porpoises were permanently housed in the "Fjord and Bælt" (F\&B) on the northern side of the harbor (see Fig. 1). Their enclosure is a rectangu-

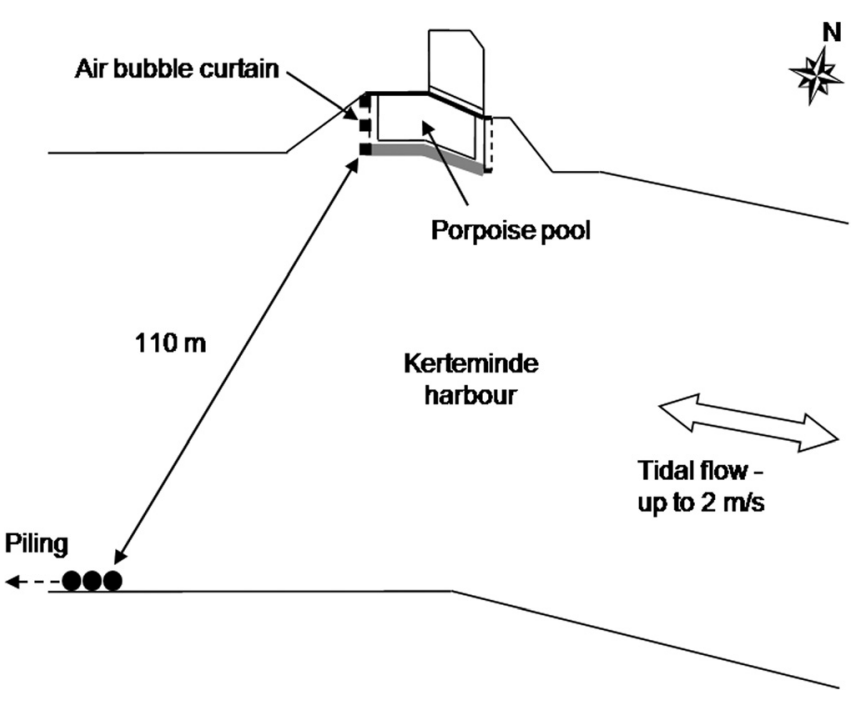

FIG. 1. Schematic overhead view of Kerteminde harbor with the "Fjord and Bælt" located on its northern side and the piling activity (indicated by black dots and dashed arrow) carried out on the southern side. Due to tidal influence from the Great Belt currents of up to $2 \mathrm{~m} / \mathrm{s}$ can occur in Kerteminde harbor. The dotted line indicates the position of the air bubble curtain. The solid black and gray lines indicate the closed sides of the enclosures, the dashed lines show the position of the nets.

lar semi-natural outdoor-pool along the fishing harbor of Kerteminde. Its dimensions are $20 \mathrm{~m}$ by $30 \mathrm{~m}$, with an average depth of $4 \mathrm{~m}$. While the long sides are formed by concrete and steel walls, both shorter ends of the enclosure are separated from the harbor by nets thus providing a permanent water exchange and an unobstructed sound coupling with the adjacent harbor.

With the piling activity slowly moving upstream, the distance from the pile driver to the harbor porpoises enclosure increased from $100 \mathrm{~m}$ to $175 \mathrm{~m}$. The harbor porpoises showed strong avoidance reactions after the start of the piling activities. This involved rapid surfacing, movement to the far end of enclosure away from the sound source, and an abnormal resting behavior at the surface at the far end of their enclosure over several minutes. As a measure to reduce the sound exposure for the animals an $\mathrm{ABC}$ was constructed and operated in a direct path between the piling site and the adjacent opening of the animals' semi-natural pool.

The piling activity was suspended for the duration of the construction and installation of the $\mathrm{ABC}$ system. The system had a total length of approximately $40 \mathrm{~m}$ and was constructed using $40 \mathrm{~mm}$ outer diameter semi-rigid plastic hose (polyvinyl chloride, $2 \mathrm{~mm}$ wall thickness) with $2 \mathrm{~mm}$ diameter holes spaced $100 \mathrm{~mm}$ apart along its length. The hose was laid on the seabed along the eastern side of the porpoise enclosure (i.e., the side facing the piling site) for $20 \mathrm{~m}$ at a depth of 3$5 \mathrm{~m}$ depending on the tide $( \pm 1 \mathrm{~m})$. A maximum tidal current of up to $0.5 \mathrm{~m} / \mathrm{s}$ was measured in the water column at the eastern side of the animals' enclosure. Due to this current, a double-hose design was chosen and the second half of the hose was doubled back at approximately mid-water (1.5$3.5 \mathrm{~m}$ depth) along the same path. This ensured that air bubbles formed a more uniform surface in relation to the incoming sound wave and decreased the effect of dispersion due to the water currents as the bubbles rise. The doubling of 
the hose also increased the total amount of air available within the $20 \mathrm{~m}$ aperture across the enclosure to form the ABC. A compressor was used to provide air at a flow rate of $5 \mathrm{~m}^{3}$ $\min ^{1}$ at a 5 bar pressure. The compressor was placed approximately $40 \mathrm{~m}$ away in a nearby parking lot and was not expected to contribute directly to noise in the water column.

An air pressure gradient was found inside the hoses, with the highest pressure at the lower hose next to the landside (closest to the compressor), decreasing toward the harbor wall and lowest at the upper hose at land-side. Due to the folding back of the hose, this bi-directional gradient led to a relatively even distribution of air bubbles along the bubble curtain.

Moderately strong currents $\left(0.5 \mathrm{~m} \mathrm{~s}^{-1}\right)$ were observed at the position of the ABC system both during flood and ebb tides. These currents resulted in a larger dispersion of the bubble field from the lower line and more drifting as the current had more time to act on the rising bubbles. The displacement and dispersion of the lower bubble field swung left and right of the upper field depending on the state of the tide.

An assessment of the bubble field's state is clearly critical to any acoustic properties measured. In practice, however, the field is highly variable in bubble size, shape, coverage, etc., and depends on input air flow and air pressure, outlet depth, outlet mechanism (lots of small holes or wider spaced bigger holes), currents, and bubble rise depth. To inspect the bubble curtain and assess the air bubble field at various points during acoustic tests, an underwater camera was deployed within the bubble field. From this it was possible to observe the overall bubble field coverage. Figure 2 shows a sample of bubble field at the upper hose line.

\section{A. Piling and air bubble curtain noise assessment}

Received level measurements of the piling noise on either side of the bubble curtain were made in the direction of the piling source at a point of the enclosure closest to piling. Two identical hydrophones (Reson TC 4033) were deployed $2 \mathrm{~m}$ from either side of the air bubble curtain in a direct line to the source approximately perpendicular to the air bubble curtain at $2 \mathrm{~m}$ water depth (i.e., approximately mid-water depth,

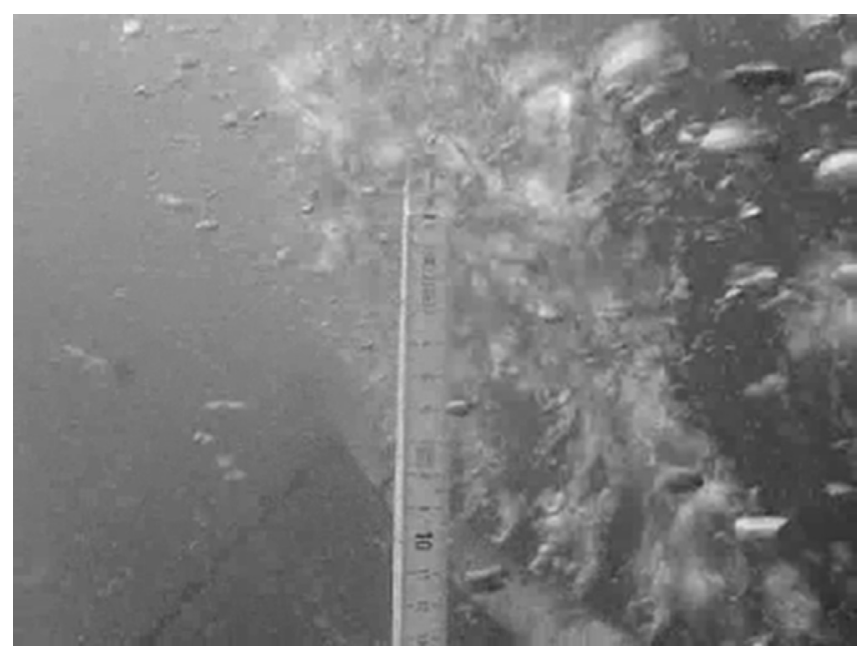

FIG. 2. Upper bubble field of operational air bubble curtain viewed along hose line. Scale $30 \mathrm{~cm}$ from lens. depending on state of tide). Simultaneous recordings of piling impulses in front of and behind the bubble curtain were made using two identical hydrophone and data acquisition systems, detailed below. The range $(110 \mathrm{~m})$ from bubble curtain to piling source was assessed using a laser range finder.

Measurements were made using calibrated hydrophones (Reson TC 4033) with additional $30 \mathrm{~dB}$ of gain (Etec B1501, with Butterworth band pass filters from $10 \mathrm{~Hz}$ to $180 \mathrm{kHz}$ with a $12 \mathrm{~dB} /$ octave roll off). The signals were recorded directly to hard disc using a National Instruments DAQ card $6062 \mathrm{E}$ at 12 bit resolution and a $320 \mathrm{kHz}$ sample rate and a custom software package SeaProDAQ (Pavan et al., 2001). The ambient noise measurements with and without the air bubble curtain being turned on were made using identical hydrophone and data acquisition set-ups and positioning shortly before or after piling events.

\section{B. Behavioral observation}

Concurrently to the installation and operation of the $\mathrm{ABC}$, the harbor porpoises' behavior was observed during and after the pile driving period. The method used was a focal sampling (Altmann, 1974) of all three animals over a period of $10 \mathrm{~min}$ at randomly varied times of the day. The behavioral data were submitted to statistical analyses (using a mixed effect model with animal ID as random variable) to reveal significant changes during the observation period.

\section{RESULTS}

An example typical simultaneous time domain waveforms from a single piling impact with the air bubble curtain on are shown in Fig. 3 with Fig. 3 (top) showing the received signal on the outer hydrophone (nearest to the sound source) and Fig. 3 (bottom) showing equivalent pulse on the inner hydrophone (on far side of the air bubble curtain). In the case of the outer hydrophone a received sound pressure level of $181 \mathrm{~dB}$ re $1 \mu \mathrm{Pa}$ (peak-peak, i.e., difference between maximum positive and maximum negative amplitudes) of the
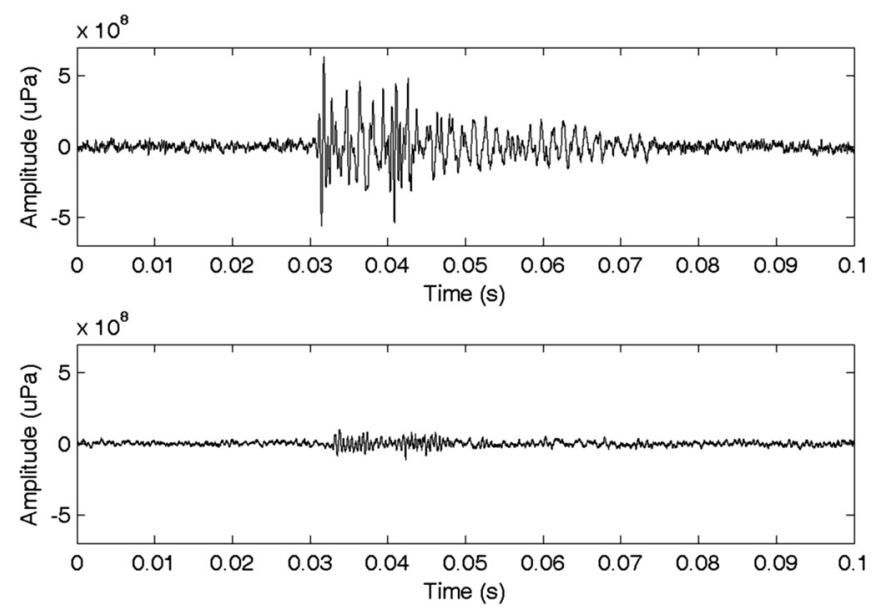

FIG. 3. Comparison of waveforms of a typical piling signal recorded simultaneously inside and outside an air bubble curtain (ABC) at a distance of $110 \mathrm{~m}$ from the piling site. The received sound pressure levels and sound energy are given for both recordings. The hydrophones were positioned at a $2 \mathrm{~m}$ distance from the air bubble curtain at a $2 \mathrm{~m}$ water depth. 
combined noise of the piling impulse and the air bubble curtain noise was observed with an single impulse SEL of 149 $\mathrm{dB}$ re $1 \mu \mathrm{Pa}^{2}$ s based on a $90 \%$ energy criteria [SEL 90 , as explained in Madsen (2005)]. This can be compared with a received sound pressure level of $166 \mathrm{~dB}$ re $1 \mu \mathrm{Pa}$ (peak-peak) and $135 \mathrm{~dB}$ re $1 \mu \mathrm{Pa}^{2}$ s for peak-peak and SEL respectively on the inner hydrophone. Over a complete piling sequence relatively high variations in received levels were observed. For one sequence of 95 strikes the received level at the outer hydrophone varied between 168 and $181 \mathrm{~dB}$ re $1 \mu \mathrm{Pa}$ (peakpeak) with an SEL90 level between 137 and $149 \mathrm{~dB}$ re $1 \mu \mathrm{Pa}^{2}$ s. Comparable results were observed on data from three consecutive pile driving sequences.

Figure 4 shows direct comparison of the difference in received sound pressure levels from simultaneous recordings made on both sides of the air bubble curtain for an entire piling sequence of 95 strikes. The difference in spreading loss between the outer (closer to pile) and inner hydrophone (further from pile) was estimated using a worst case spherical spreading loss from the ranges $108 \mathrm{~m}$ to a $112 \mathrm{~m}$ giving a loss difference of less than $0.32 \mathrm{~dB}$; however, propagation within the water column from the pile of over 20 water depths is likely to result in still lower loss difference between the hydrophone positions due to spreading and was therefore considered negligible in the attenuation estimates.

For both peak-peak and SEL values a clear reduction can be seen across the $\mathrm{ABC}$ for levels similar to that seen in the single strike example shown in Fig. 3.

In the case of the continuous sequence shown in Fig. 4 the mean level difference between inside and outside the air bubble curtain of $14 \mathrm{~dB}$ for peak-peak values and $13 \mathrm{~dB}$ for
SEL values were observed. The peak-peak values have a higher standard deviation of $3.4 \mathrm{~dB}$ compared to $2.5 \mathrm{~dB}$ for the SEL value across the sequence.

The spectral contents of both piling impulse and of the air bubble curtain's self noise were also measured. Figure 5 shows the power spectral density integrated across third octave bands for a $100 \mathrm{~ms}$ time window (chosen to cover the entire pulse duration as seen at the hydrophone) for five cases including simultaneous hammer strike on inner and outer hydrophones, the period of background level just before hammer strikes (approximately $1.5 \mathrm{~s}$ after previous strike) on both inner and outer hydrophones with bubble curtain on and background level before bubble curtain was activated. In the time domain the signal (Fig. 3) shows no significant reverberation after around $100 \mathrm{~ms}$ after the main signal arrival; therefore, consecutive pulses were considered in isolation. The results in Fig. 5 are presented as spectral density across third octave band calculated by division of the power spectral level in that band by the bands spectral width. This was done to allow direct comparison of broad band bubble noise and ambient noise to other broadband spectral density data sets.

A comparison of levels recorded at both hydrophones with the ABC turned on and off shows significant noise level increases when no piling occurred. A maximum increase of $45 \mathrm{~dB}$ above the background levels (without the air bubble curtain being activated) was observed around $600 \mathrm{~Hz}$ with levels from $500 \mathrm{~Hz}$ and $10 \mathrm{kHz}$ typically 20-30 dB above background and elevated levels for frequencies up to 50 $\mathrm{kHz}$. The difference in equivalent bubble curtain noise on the two hydrophones is most likely due to the drift of the curtain in current flow with both hydrophones were at the
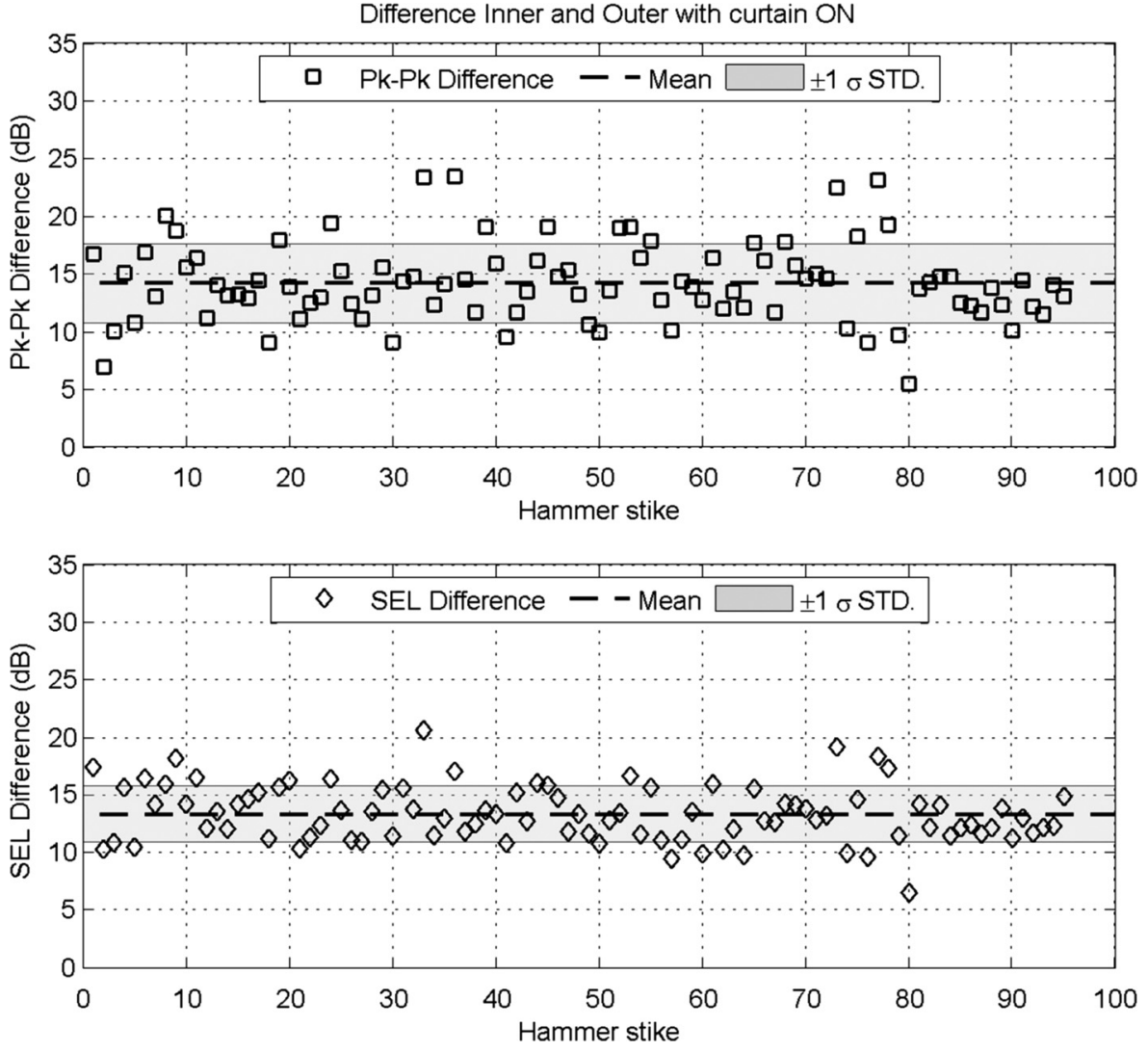

FIG. 4. (top) Difference in peak-peak level for measurements made in front of (relative to the sound source) and behind the air bubble curtain $(\mathrm{ABC})$ for 95 consecutive strikes from a single piling sequence. (bottom) Equivalent data for difference SEL level inside and outside the $\mathrm{ABC}$. 


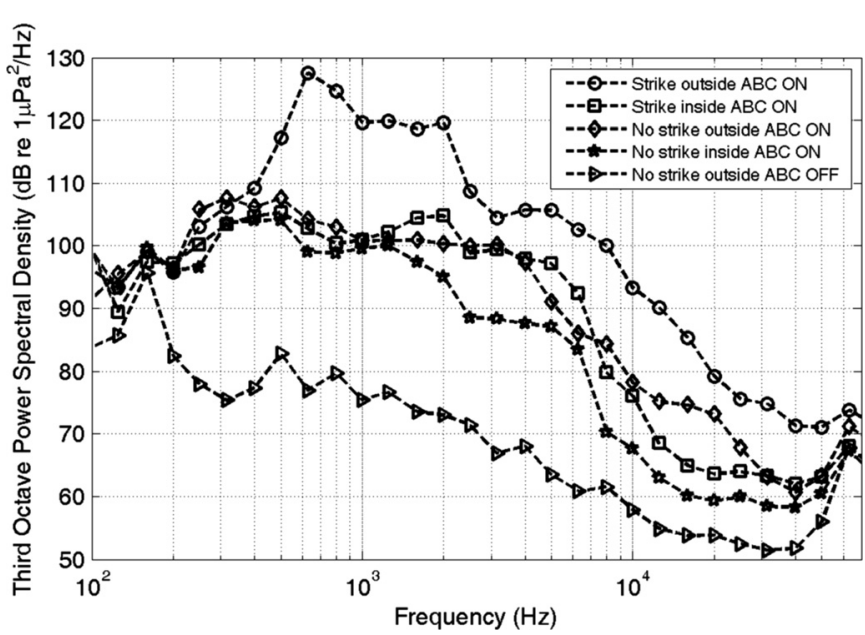

FIG. 5. Power spectral density integrated across third octave bands for five cases: a single received strike on outer hydrophone with air bubble curtain (ABC) turned on (indicated by circles), the same strike received on inner hydrophone with air bubble curtain turned on (squares), outer hydrophone period immediately before hammer strike (approximately $1.5 \mathrm{~s}$ after previous strike) with air bubble curtain turned on (diamonds) d) inner hydrophone period immediately before hammer strike with air bubble curtain turned on (stars), and background levels just before the start of piling sequence and the air bubble curtain turned off (triangles). Total time window used was $100 \mathrm{~ms}$ at a sample rate of $320 \mathrm{kS} / \mathrm{s}$.

same water depth as the upper air bubble curtain outlet jets with a range of $2 \mathrm{~m}$.

With the bubble curtain on the level at the outer hydrophone increased due to the hammer strike at frequencies from $400 \mathrm{~Hz}$ up to greater than $50 \mathrm{kHz}$ above the equivalent no-strike noise level. The most dominant frequency content was seen around $600 \mathrm{~Hz}$, with an equivalent increase of approximately $20 \mathrm{~dB}$.

By comparison the levels on the inner hydrophone were 10-20 dB lower for frequencies 500-2000 Hz in overall level compared with the outer hydrophone. With the ABC turned on no significant hammers strike signal was observed on the inner hydrophone for frequencies 400-1000 Hz suggesting attenuation of these hammer strike components to levels below the background noise level of the operational $\mathrm{ABC}$. The most dominant frequency content observed on the inner hydrophone above the no-strike background noise was around $2-6 \mathrm{kHz}$ with a maximum difference of around 12 $\mathrm{dB}$ above equivalent noise levels before and during hammer strike with the air bubble curtain is turned on. The difference in strike and equivalent noise level was reduced to less than $5 \mathrm{~dB}$ for frequencies greater than $10 \mathrm{kHz}$. All noise measurements were conducted when no boat traffic was in the immediate vicinity under calm conditions without rain.

\section{A. Behavioral reaction}

With the onset of the piling activity, the three harbor porpoises (one adult male, one adult female, and a juvenile female) in the enclosure immediately displayed strong behavioral reactions such as speed swimming and porpoising for as long as the piling continued. These behaviors were interpreted as avoidance reactions to the sound exposure as they had been observed in these animals during exposures to novel acoustic stimuli before and are similar to flight behavior observed in free ranging animals. These energetically demanding behaviors were in some cases followed or interrupted by periods when an animal could be observed logging at the surface at the far end of their enclosure. Due to the unexpected onset of the piling activity, no quantitative observation of the animals' behavior was conducted prior to this study. However, visual observation of the animals' overall behavior and their breathing rates in particular had been conducted routinely prior to the onset of pile driving.

Systematic observation of the porpoises revealed no further obvious avoidance behavior in response to the ramming activities or the operation of the air bubble curtain. The only avoidance reaction observed occurred when the air bubble curtain was initially activated. This reaction, however, faded within the first few days whenever the air bubble curtain was active.

\section{DISCUSSION}

The results of the acoustic data analyzed in this study show that the air bubble curtain can be an effective measure to mitigate sound-induced effects on marine mammals. The work presented here resulted as reaction to the commencement of piling activities in Kerteminde harbor, and the air bubble curtain was constructed with the best available knowledge of its potential attenuation effects. The results presented show that attenuation of this type of piling noise was achieved with mean difference between inside and outside curtain of 14 $\mathrm{dB}$ for peak-peak and $13 \mathrm{~dB}$ for SEL values.

A study on the tolerance of the animals hearing to intense impulsive sounds revealed that harbor porpoises are likely to show a temporary threshold shift (TTS) in their hearing sensitivity at a received sound pressure level above $200 \mathrm{~dB}$ (peak-peak) re $1 \mu \mathrm{Pa}$ or a received sound energy above $164 \mathrm{~dB}$ re $1 \mu \mathrm{Pa}^{2}$ s (Lucke et al., 2009). A reduction in sound level by $14 \mathrm{~dB}$ on average-as achieved with this system-would reduce the range of this effect around a sound source by over $75 \%$ and the affected area by over $90 \%$ (assuming spherical spreading with a propagation loss of $20 \cdot \log (r)$, with $r=$ range in meters).

The effectiveness of such an air bubble system in open waters based on the results of this study remains difficult to assess. With stronger currents and greater water depths in which such a system could possibly be installed the efficiency of the present design may have to be optimized. One beneficial aspect of the chosen design was the installation of the bubble curtain near the sound receivers (the animals), thus avoiding the problem of bottom propagation in this captive situation to some extent. The transmission of some sound energy through the bottom may contribute to the received level at the animals due to reemergence of the sound back into the water column. This effect of sediment borne energy on received level in the water column would potentially be worse if the sound barrier is placed nearer to the sound source giving more time for the sediment borne energy to reemerge into the water column.

The porpoises generally resumed normal activity during piling when the bubble curtain was activated. Porpoising and 
speed swimming, along with an increased breathing rate, as observed during the initial period of pile driving before the $\mathrm{ABC}$ was constructed, are likely indicators of increased stress in the animals. No long lasting behavior of this type was observed after the air bubble curtain was installed. The null-hypothesis in this context was that the animals behaved in the same way when pile driving noise was present or absent and regardless of the air bubble curtain. As no quantitative data exist on the animals' behavioral response to the pile driving without the air bubble curtain in operation and no statistically significant differences were found during the remaining scenarios (pile driving without operational air bubble curtain as well as no pile driving with and without air bubble curtain) these data have to be treated as anecdotal evidence. Moreover, additional factors such as habituation to the piling noise over time and reduced sound levels as the piling moved away from the enclosure could have also influenced the behavior. It also remains unclear to what extent the behavioral reaction of harbor porpoises held under human care in a comparatively noisy fishing harbor can be used as proxies for wild animals. Nevertheless, any attenuating effect would result in a smaller range around a sound source in which behavioral reactions would occur. Tougaard et al. (2003) observed a significant increase in directional movement of wild harbor porpoises away from a site (Horns Rev, Denmark) where foundations were driven into the ground by using impulsive pile driving.

The planned expansion of wind farm developments in European waters will potentially lead to thousands of wind turbines being installed over the next decades. This would increase the percentage of the whole population of harbor porpoises that could be affected at least once. Moreover, it is likely that individual animals would be exposed repeatedly to pile driving sounds. This could occur if the animals return to the same site and experience the sound emissions from the installation of the next foundation or move to other areas where a different wind farm is under construction.

At time of writing there was very little data available for any marine mammal species on cumulative effects from repeated exposure to intense sounds. One recent study by Finneran et al. (2010) confirmed the potential for accumulation for TTS across multiple exposures to $16 \mathrm{~s}$ long acoustic stimuli for bottlenose dolphin (Tursiops truncatus). Similarly a TTS study in harbor porpoises (Lucke et al., 2009) provided first data on the recovery time of the animals' auditory system after exposure to impulses above its TTS threshold. This indicates that harbor porpoises need long periods (up to days) to recover from TTS. Any repeated exposure within this period would lead to a summation effect and aggravate the auditory effect. Furthermore, cumulative non-acoustic effects could potentially also arise from acoustic effects in conjunction with other environmental stressors such as pollution and food depletion.

The results presented here show that air bubble curtains can provide the opportunity to reduce acoustically induced detrimental effects at least to some degree. Any attenuation effects would help mitigate overall received levels around a noise source reducing overall impact on the marine environment.

\section{ACKNOWLEDGMENTS}

We would like to thank the Kerteminde local council, the Kerteminde harbor master and Mogens Pedersen, Nyborg, Denmark, for their logistical support. The staff of Fjord and Bælt, Kerteminde, Denmark, was extremely helpful during the study, and we would like to especially thank Louise Jacobsen. We also thank Janne Sundermeyer, Gordon Leonard, and Simon Dible, Loughborough University, for their support during setup and testing of the bubble curtain and Stephen Robinson from the National Physical Laboratory (UK) for analysis software support. Valuable advice was given by Bernd Würsig, Texas A\&M, Tim Leighton, University of Southampton, Charles Greene, Greeneridge Sciences Inc., and Mats Amundin, Kolmårdens Djurpark. We would like to acknowledge their contribution to the outcome of this study. We would also like to thank Christiane Siebert for a thorough linguistic review of the manuscript and Sven Adler as well as Roger Mundry for statistical advice.

Altmann, J. (1974). "Observational study of behaviour: Sampling methods," Behaviour 49, 227-267.

Andersen, S. (1970). "Auditory sensitivity of the harbour porpoise Phocoena phocoena," in Investigations in Cetacea, edited by G. Pilleri (Museum of Natural History, Paciano), Vol. 2, pp. 255-259.

California Department of Transportation (2001). "San Francisco - Oakland Bay Bridge East Span Seismic Safety Project,” PIDP EA 012018, Pile Installation Demonstration Project, Marine Mammal Impact Assessment (California Department of Transportation, Sacramento, CA), pp. 65.

De Jong, C. A. F., and Ainslie, M. A. (2008). "Underwater radiated noise due to the piling for the Q7 offshore wind park," Proceedings of Acoustics 08 (Paris, France), pp. 2987.

Finneran, J. J., Schlundt, C. E., Dear, R., Carder, D. A., and Ridgway, S. H. (2002). "Temporary shift in masked hearing thresholds in odontocetes after exposure to single underwater impulses from a seismic watergun," J. Acoust. Soc. Am. 111, 2929-2940.

Finneran, J. J., Carder, D. A., Schlundt, C. E., and Ridgway, S. H. (2005). "Temporary threshold shift in bottlenose dolphins (Tursiops truncatus) exposed to mid-frequency tones," J. Acoust. Soc. Am. 118(4), 26962705.

Finneran, J. J., Carder, D. A., Schlundt, C. E., and Dear, R. L (2010). "Temporary threshold shift in bottlenose dolphins (Tursiops truncatus) exposed to intermittent tones," J. Acoust. Soc. Am. 127(5), 3267-3272.

Gordon, J. C., Gillespie, D., Potter, J. R., Frantzis, A., Simmonds, M. P., Swift, R., and Thompson, D. (2004). "A review of the effects of seismic surveys on marine mammals," Mar. Tech. Soc. J. 37, 16-34.

Hawkins, A. D. (2009). "The impact of pile driving upon fish," Proc. Inst. Acoust. 31(1), 72-79.

Kastelein, R. A., Bunskoek, P., Hagedoorn, M., and Au, W. W. L. (2002). "Audiogram of a harbour porpoise (Phocoena phocoena) measured with narrow-band frequency-modulated signals," J. Acoust. Soc. Am. 112(1), 334-344.

Lucke, K., Lepper, P. A., Blanchet, M.-A., and Siebert, U. (2009). "Temporary shift in masked hearing thresholds in a harbor porpoise (Phocoena phocoena) after exposure to seismic airgun stimuli," J. Acoust. Soc. Am. 125(6), 4060-4070.

Madsen, P. T. (2005). "Marine mammals and noise: Problems with root mean square sound pressure levels for transients," J. Acoust. Soc. Am. 117(6), 3952-3957.

Madsen, P. T., Wahlberg, M., Tougaard, J., Lucke, K., and Tyack, P. (2006). "Wind turbine underwater noise and marine mammals: Implications of current knowledge and data needs-Review," Mar. Ecol. Prog. Ser. 309, 279-295.

Mallock, A. (1910). "The damping of sound by frothy liquids," Proc. R. Soc. London A 84(572), 391-395.

Matuschek, R., and Betke, K. (2009). "Measurment of construction noise during pile driving of offshore research platforms and wind farms," Proceedings of NAG/DAGA 2009 International Conference on Acoustics (Rotterdam, Netherlands), pp. 262-265. 
Nachtigall, P. E., Pawlowski, J., and Au, W. W. L. (2003). "Temporary threshold shifts and recovery following noise exposure in the Atlantic bottlenosed dolphin (Tursiops truncatus)," J. Acoust. Soc. Am. 113, 3425-3429.

Nachtigall, P. E., Supin, A. Ya., Pawlowski, J., and Au, W. W. A. (2004). "Temporary threshold shifts after noise exposure in the bottlenose dolphin (Tursiops truncatus) measured using evoked auditory potentials," Mar. Mamm. Sci. 20, 673-687.

NRC (2000). Marine Mammals and Low-Frequency Sound (National Academy Press, Washington, DC), pp. 146

NRC (2005). Marine Mammal Populations and Ocean Noise, National Academic Press, Washington, D.C., $126 \mathrm{pp}$

Pavan, G., Manghi, M., and Fossati, C. (2001). "Software and hardware sound analysis tools for field work," Proceedings of the 2nd Symposium on Underwater Biosonar and Bioacoustic Systems, I.O.A. Institute of Acoustics, Loughborough UK, 23(4), 175-183.

Reyff, J. A. (2003a). "Underwater sound pressure associated with the restrike of the pile installation demonstration project piles," Department of Transportation, State of California, Sacramento, CA, pp. 33.

Reyff, J. A. (2003b). "Underwater sound levels associated with construction of the Benicia-Martinez Bridge, acoustical evaluation of an unconfined air-bubble curtain system at Pier 13," Department of Transportation, State of California, Sacramento, CA, pp. 25.

Reyff, J. A. (2009). "Underwater sounds from marine pile driving," Internoise 2009, Ottawa, Canada, October 23-26, 2009, pp. 250.

Robinson, S. P., Lepper, P. A., and Ablitt, J. (2007). "The measurement of the underwater radiated noise from marine piling including characterisation of a 'soft start' period," OCEAN 2007, Insititute of Electronical and Electronics Engineers Conference, Aberdeen, UK, pp. 1-6.

Richardson, W. J., Greene, C. R. Jr., Malme, C. I., and Thomson, D. H. (1995). Marine Mammals and Noise (Academic Press, San Diego), 576 pp.
Rodkin, R. B., and Reyff, J. A. (2007). "Underwater sound from marine pile driving," Bioacoustics 17, 138-140.

Southall, B. L., Bowles, A. E., Ellison, W. T., Finneran, J. J., Gentry, R. L., Greene, C. R., Jr., Kastak, D., Ketten, D. R., Miller, J. H., Nachtigall, P. E., Richardson, W. J., Thomas, J. A., and Tyack, P. L. (2007). "Marine mammal noise exposure criteria: Initial scientific recommendations," Aquat. Mamm. 33(4), 411-521.

Tougaard, J., Carstensen, J., Henriksen, O. D., Skov, H., and Teilmann, J. (2003). "Short-term effects of the construction of wind turbines on harbour porpoises at Horns Reef," Technical report HME/362-02662, Hedeselskabet, Roskilde, pp. 72.

Tougaard, J., Carstensen, J., Teilmann, J., and Bech, N. I. (2005). "Effects of the Nysted offshore wind farm on harbour porpoises. Annual status report for the T-POD monitoring program," Technical Report Energi E2 A/S, NERI, Roskilde, pp. 49.

Tougaard, J., Carstensen, J., Wisz, M., Jespersen, M., Teilmann, J., Bech, N. I., and Skov, H. (2006). "Harbour porpoises on Horns Reef - Effects of the Horns Reef wind farm, " NERI Technical report, Roskilde, pp. 111.

Tougaard, J., Carstensen, J., Henriksen, Teilmann, J. O. D., Skov, H., and Rasmussen, P. (2009). "Pile driving zones of responsiveness extends beyond $20 \mathrm{~km}$ for harbor porpoises (Phocoena phocoena (L.)) (L)," J. Acoust. Soc. Am. 126(1), 11-14.

Urick, R. J. (1983). Principles of Underwater Sound, (McGraw-Hill, New York), pp. 423.

Vagle, S. (2003). On the Impact of Underwater Pile-Driving Noise on Marine Life, Institute of Ocean Sciences (Fisheries \& Oceans Canada, DFO/ Pacific, Canada), pp. 41.

Würsig, B., Greene, C. R. Jr. and Jefferson, T. A. (2000). "Development of an air bubble curtain to reduce underwater noise of percussive piling," Mar. Environ. Res., 49, 79-93. 